\title{
High Reflectivity of Silver Extended Down to 200 NM
}

\author{
N. Thomas, J. Wolfe
}

This article was submitted to

Optical Society of America's Eighth Topical Meeting on Optical Interference Coatings, Alberta, Canada, July 15-20, 2001

\section{June 4, 2001}

Lawrence

Livermore

National

Laboratory 


\section{DISCLAIMER}

This document was prepared as an account of work sponsored by an agency of the United States Government. Neither the United States Government nor the University of California nor any of their employees, makes any warranty, express or implied, or assumes any legal liability or responsibility for the accuracy, completeness, or usefulness of any information, apparatus, product, or process disclosed, or represents that its use would not infringe privately owned rights. Reference herein to any specific commercial product, process, or service by trade name, trademark, manufacturer, or otherwise, does not necessarily constitute or imply its endorsement, recommendation, or favoring by the United States Government or the University of California. The views and opinions of authors expressed herein do not necessarily state or reflect those of the United States Government or the University of California, and shall not be used for advertising or product endorsement purposes.

This is a preprint of a paper intended for publication in a journal or proceedings. Since changes may be made before publication, this preprint is made available with the understanding that it will not be cited or reproduced without the permission of the author.

This work was performed under the auspices of the United States Department of Energy by the University of California, Lawrence Livermore National Laboratory under contract No. W-7405-Eng-48.

This report has been reproduced directly from the best available copy.

Available electronically at http://www.doc.gov/bridge

Available for a processing fee to U.S. Department of Energy

And its contractors in paper from

U.S. Department of Energy

Office of Scientific and Technical Information

P.O. Box 62

Oak Ridge, TN 37831-0062

Telephone: (865) 576-8401

Facsimile: (865) 576-5728

E-mail: reports@adonis.osti.gov

Available for the sale to the public from

U.S. Department of Commerce

National Technical Information Service

5285 Port Royal Road

Springfield, VA 22161

Telephone: (800) 553-6847

Facsimile: (703) 605-6900

E-mail: orders@ntis.fedworld.gov

Online ordering: http://www.ntis.gov/ordering.htm

\section{OR}

Lawrence Livermore National Laboratory

Technical Information Department's Digital Library

http://www.llnl.gov/tid/Library.html 


\title{
High Reflectivity of Silver Extended Down to 200 NM
}

\author{
Norman Thomas and Jesse Wolfe \\ Lawrence Livermore National Laboratory \\ University of California, Livermore, CA 94550
}

\begin{abstract}
Silver has the highest reflectance of all of the metals, but it tarnishes in the presence of sulfides, chlorides, and oxides in the atmosphere. Also, the silver reflectance is very low at wavelengths below $400 \mathrm{~nm}$ making aluminum more desirable mirror coating for the UV region. We have found a way to prevent silver tarnishing by sandwiching the silver layer between two thin layers of $\mathrm{NiCrN}_{\mathrm{x}}$, and to extend the metal's high reflectance down to $200 \mathrm{~nm}$ by depositing the (thin) Ag layer on top of Al. Thus, the uv is transmitted through the thin Ag layer below $400 \mathrm{~nm}$ wavelength, and is reflected from the Al layer underneath. This UV-shifted durable coating ${ }^{1}$ provides a valuable alternative to the aluminum coating for telescope mirror coatings where collection efficiency is an important consideration.
\end{abstract}

\section{Introduction}

Evaporated silver on mirror substrates has several advantages compared to other metals. It has the highest reflectivity from $400 \mathrm{~nm}$ through the infrared and the lowest polarization splitting compared to any other metal. Figure 1 compares the reflectance for silver, aluminum and gold. The disadvantage of bare silver is that it tarnishes under ordinary atmospheric conditions and does not have a high reflectance below $400 \mathrm{~nm}$. There is a minimum reflectance at $320 \mathrm{~nm}$ due to a surface plasmon resonance. Aluminum, on the other hand, has a dip in reflectance at $850 \mathrm{~nm}$ due to inter-band transitions, but reflects well down to $280 \mathrm{~nm}$, the cutoff for atmospheric transmission. If a thin layer of silver is deposited on aluminum, the advantages of silver and aluminum are combined: silver reflects for $\lambda>400 \mathrm{~nm}$ and masks the dip at $850 \mathrm{~nm}$, and aluminum reflects for $\lambda<400 \mathrm{~nm}$ where silver is semi-transparent.

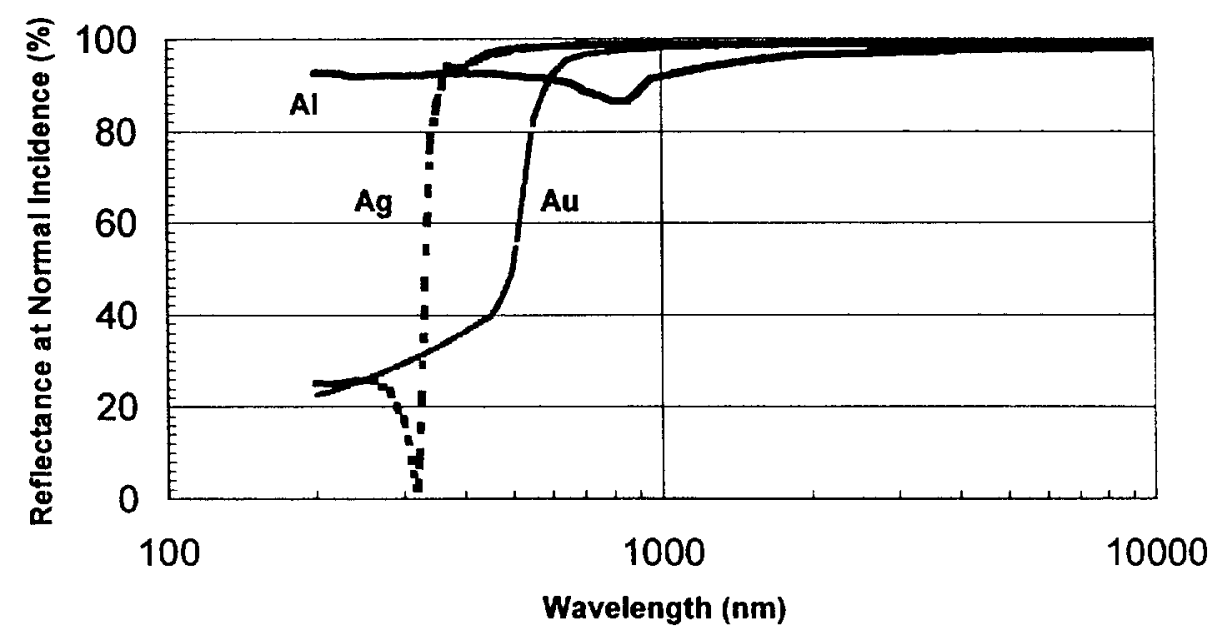

Fig. 1 Reflectance of evaporated metals in the visible and infrared 
Silver is a noble metal which is completely stable in aqueous solutions of any $\mathrm{pH}$ as long as oxidizing agents or complexing substances are not present. In the presence of such substances, the high specular reflectivity of silver is degraded by sulfidation, chloridation and oxidation with corrosive chemicals in the atmosphere such as $\mathrm{H}_{2} \mathrm{~S}, \mathrm{O}, \mathrm{O}^{=}, \mathrm{H}_{2} \mathrm{O}_{2}, \mathrm{SO}_{2}, \mathrm{CL}^{-}$, etc. The corrosion products of silver are $\mathrm{Ag}_{2} \mathrm{~S}, \mathrm{AgCl}$, $\mathrm{Ag}_{2} \mathrm{O}, \mathrm{Ag}_{2} \mathrm{SO}_{4}$ and $\mathrm{Ag}_{2} \mathrm{CO}_{3}$ in increasing order of solubility. Since these products form in the thin water layer which is typically present on silver, the most likely precipitate is $\mathrm{Ag}_{2} \mathrm{~S}$. Sandwiching the silver layer between two thin layers of $\mathrm{NiCrN}_{\mathrm{x}}$ was shown to stop these corrodants from lowering silver reflectance.

\section{Thin Film Design}

The basic coating design is shown in Figure 2. The materials for the enhancement layers are listed for three different coating designs: Phase I, II, and III. The Phase I design extends the high reflectance of silver down to $300 \mathrm{~nm}$; Phase II shifts it down to $250 \mathrm{~nm}$; and Phase III shifts down to $200 \mathrm{~nm}$. The Phase III design meets the needs for many astronomical applications.

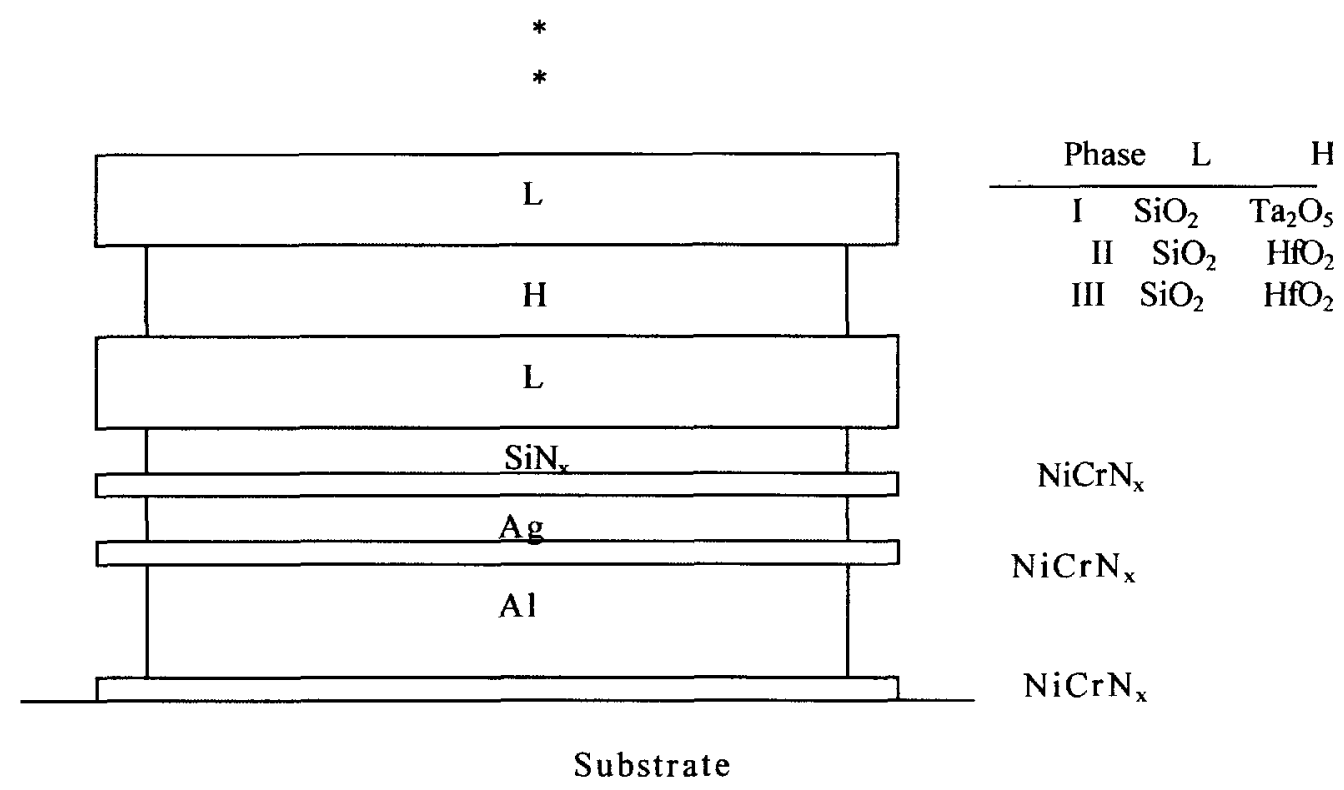

Fig. 2 Coating Design

The adhesion layer provides nucleation sites on the substrate for the sputtered silver, and works in combination with the $\mathrm{NiCrN}_{\mathrm{x}}$ layer to improve mechanical and chemical durability. The $\mathrm{NiCrN}_{\mathrm{x}}$ layer alloys with the silver and helps in preventing sulfides, chlorides and oxides from reacting with the silver. The silicon nitride layer ( 30 Angstroms physical thickness) improves mechanical durability and acts as a barrier layer preventing corrodants from reacting with the silver. The metal oxide layers are combinations of silica, tantala or hafnia and serve to increase the uv reflectance.

The essence of the uv-shifted durable silver coating is the thin silver layer $(\sim 300-500$ Angstroms physical thickness) on top of an aluminum layer and the encapsulation of the silver layer between two thin layers of nickel chrome nitride (8-10 Angstroms physical thickness). Below about $380 \mathrm{~nm}$, incident light is transmitted through the silver layer and reflected by the aluminum layer. Figure 3 compares the theoretical reflectivity for Phase I, II and III to bare Ag. 


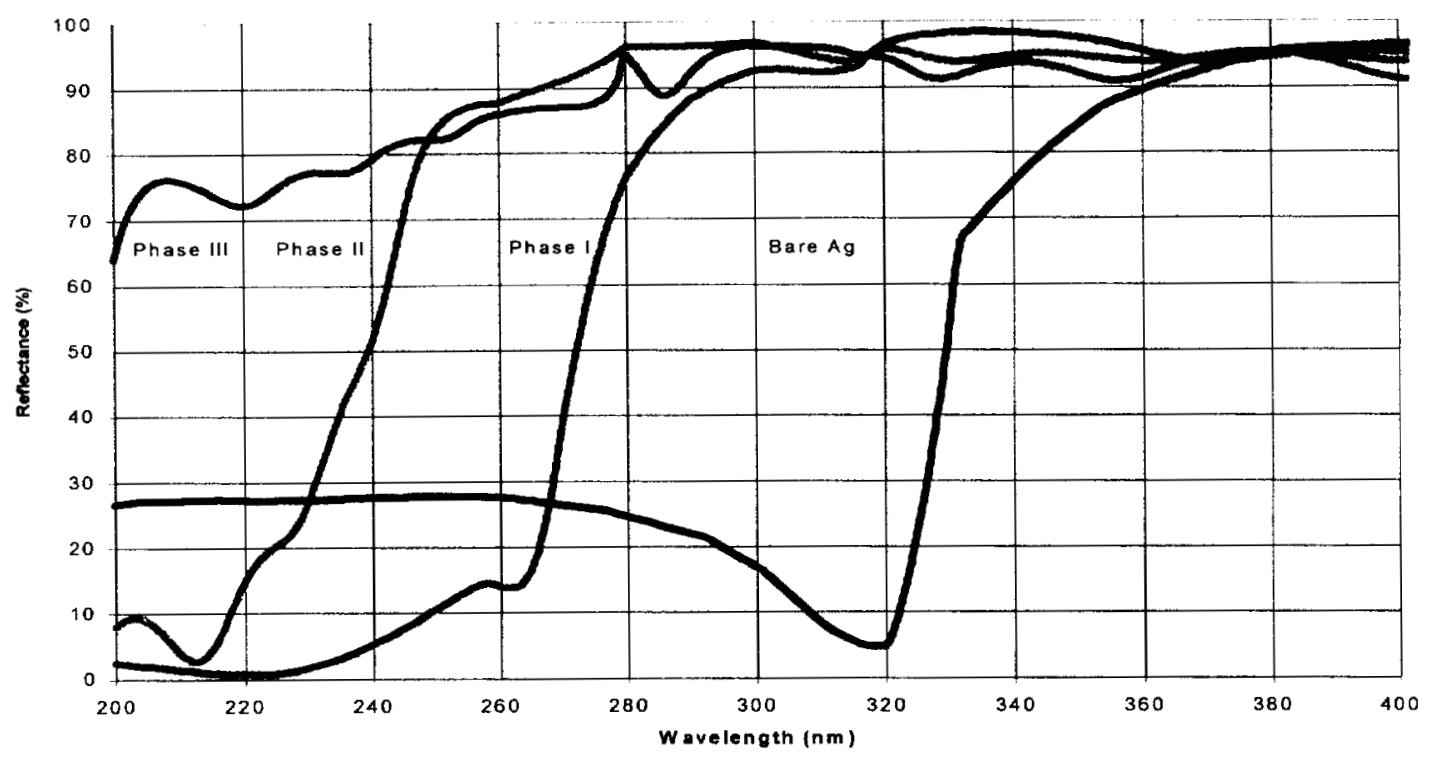

Fig. 3 Theoretical reflectance of Phase I, II, and III coating designs compared to bare silver.

\section{Result and Conclusions}

Phase I design was successfully coated on a 22-inch diameter collimator mirror from the HRIS instrument package on the Keck Telescope. This durable silver coating had an average reflectance of $>94 \%$ from $280 \mathrm{~nm}$ to $>2500 \mathrm{~nm}$ which is shown in Figure 4. The deposition geometry for this coating is described by Jesse Wolfe in another paper at this conference. Earlier, Phase III was successfully coated for an evaluation study for Hubble Space Telescope. Both coatings passed Mil-Spec 13508.

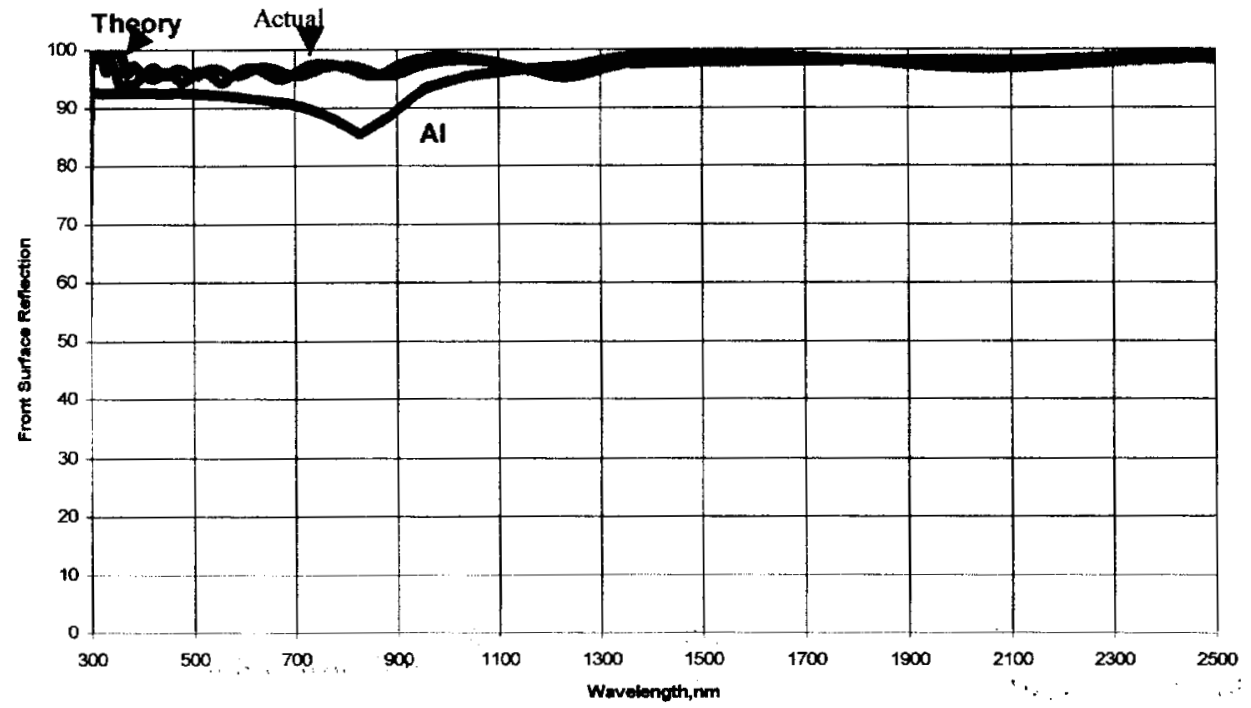

Fig. 4 Actual and theoretical reflectance for Keck mirror compared to aluminum.

1. "UV-Shifted Durable Silvet Coating for Astronomical Mirrors", Norman Thomas and tesse Wolfe, SPIE 40b3-49, Amich, Germany, March, 2000. 